\title{
A Fluorine-19 Magnetic Resonance Probe, Shiga-Y5, Downregulates Thioredoxin-Interacting Protein Expression in the Brain of a Mouse Model of Alzheimer's Disease
}

\author{
Aslina Pahrudin Arrozi (D), Zulzikry Hafiz Abu Bakar, Hiroyasu Taguchi, Daijiro Yanagisawa * \\ and Ikuo Tooyama * (D)
}

check for

updates

Citation: Pahrudin Arrozi, A.; Abu Bakar, Z.H.; Taguchi, H.; Yanagisawa, D.; Tooyama, I. A Fluorine-19 Magnetic Resonance Probe, Shiga-Y5, Downregulates ThioredoxinInteracting Protein Expression in the Brain of a Mouse Model of Alzheimer's Disease. Molecules 2021, 26, 5342. https://doi.org/10.3390/ molecules26175342

Academic Editor: Carlos Geraldes

Received: 30 July 2021

Accepted: 31 August 2021

Published: 2 September 2021

Publisher's Note: MDPI stays neutral with regard to jurisdictional claims in published maps and institutional affiliations.

Copyright: (C) 2021 by the authors Licensee MDPI, Basel, Switzerland. This article is an open access article distributed under the terms and conditions of the Creative Commons Attribution (CC BY) license (https:// creativecommons.org/licenses/by/ $4.0 /)$.

\author{
Molecular Neuroscience Research Center, Shiga University of Medical Science, Seta Tsukinowa-cho, \\ Otsu 520-2192, Japan; aslina@belle.shiga-med.ac.jp (A.P.A.); zikry@belle.shiga-med.ac.jp (Z.H.A.B.); \\ taguti@belle.shiga-med.ac.jp (H.T.) \\ * Correspondence: daijiroy@belle.shiga-med.ac.jp (D.Y.); kinchan@belle.shiga-med.ac.jp (I.T.); \\ Tel.: +81-77-548-2335 (D.Y.); +81-77-548-2330 (I.T.)
}

\begin{abstract}
Thioredoxin-interacting protein (TXNIP) is involved in multiple disease-associated functions related to oxidative stress, especially by inhibiting the anti-oxidant- and thiol-reducing activity of thioredoxin (TXN). Shiga-Y5 (SY5), a fluorine-19 magnetic resonance probe for detecting amyloid- $\beta$ deposition in the brain, previously showed therapeutic effects in a mouse model of Alzheimer's disease; however, the mechanism of action of SY5 remains unclear. SY5 passes the blood-brain barrier and then undergoes hydrolysis to produce a derivative, Shiga-Y6 (SY6), which is a TXNIP-negative regulator. Therefore, this study investigates the therapeutic role of SY5 as the prodrug of SY6 in the thioredoxin system in the brain of a mouse model of Alzheimer's disease. The intraperitoneal injection of SY5 significantly inhibited TXNIP mRNA $(p=0.0072)$ and protein expression $(p=0.0143)$ induced in the brain of APP/PS1 mice. In contrast, the levels of TXN mRNA $(p=0.0285)$ and protein $(p=0.0039)$ in the brain of APP/PS1 mice were increased after the injection of SY5. The ratio of TXN to TXNIP, which was decreased $(p=0.0131)$ in the brain of APP/PS1 mice, was significantly increased ( $p=0.0072)$ after the injection of SY5. These results suggest that SY5 acts as a prodrug of SY6 in targeting the thioredoxin system and could be a potential therapeutic compound in oxidative stress-related diseases in the brain.
\end{abstract}

Keywords: curcumin; oxidative stress; thioredoxin; TXNIP; Alzheimer's disease

\section{Introduction}

Thioredoxin-interacting protein (TXNIP) plays an important role in the redox system, but it is implicated differently in many diseases, including cancers, diabetes, and neurodegenerative disorders [1]. Additionally, TXNIP is an endogenous intracellular inhibitor of thioredoxin $(T X N)$, an anti-oxidant protein in the thiol-reductase redox system [2]. TXNIP expression is highly triggered by glucose and is increased in the beta-cells ( $\beta$-cells) of patients with diabetes [3], inhibiting TXN function and inducing increased levels of freely diffusible molecular hydrogen peroxide; it contributes to oxidative stress and eventually $\beta$-cell death [4]. Studies showed that TXNIP inhibition prevented $\beta$-cell apoptosis and protected against diabetes [5,6]. In contrast, TXNIP was underexpressed in most cancers, leading to high cell proliferation [7]. Mechanisms of TXNIP downregulation include the interaction of microRNAs with the $3^{\prime}$ untranslated region (UTR), the binding of transcription factors, and epigenetic changes in the promoter region of TXNIP [8]. Thus, inducing TXNIP expression could remarkably block the cell cycle and suppress tumor cells $[9,10]$.

TXNIP's involvement in Alzheimer's disease (AD) is mostly associated with inflammation and accompanied by other processes, such as amyloid $\beta(A \beta)$ deposition and neurofibrillary tangles $[11,12]$. Recent studies have demonstrated that TXNIP protein 
expression was upregulated and colocalized near $A \beta$ plaques and phosphorylated tau (p-tau) [13]. In contrast, in a separate study, TXN protein levels were downregulated in the brains of $\mathrm{AD}$ mice $[14,15]$. A consistent finding showed that TXNIP protein expression increased significantly in the hippocampus and frontal cortex of $A \beta$ precursor protein and presenilin 1 (APP/PS1) transgenic mice and primary cultured mouse cerebral cortex neurons HT22 mouse hippocampal cells treated with A $\beta$ peptide [16]. TXNIP remained an exclusive marker in microglia, neurons, astrocytes, and endothelial cells [17-19]. TXNIP has been proposed as an essential mediator of nucleotide-binding oligomerization domain-, leucine-rich repeat- and pyrin domain-containing 3 (NLRP3) inflammasome activation and the eventual formation of activated caspase 1 [13]. Preventing the interaction of TXNIP with NLRP3 demonstrated positive effects by reversing or restraining AD pathology [20,21]. Considering the involvement of TXNIP in the pathology of the disease, targeting these proteins might be the possible therapeutic target for intervention.

Curcumin (1,7-bis(4-hydroxy-3-methoxyphenyl)-1,6-heptadiene-3,5-dione) (Figure 1a), a polyphenol also called diferuloylmethane, is the low molecular weight yellow-orange pigment derived from a rhizomatous herbaceous perennial plant (Curcuma longa) of the ginger family known as turmeric [22]. We previously reported a novel curcumin derivative, 1,7-Bis(4'-hydroxy-3'-trifluoromethoxyphenyl)-4-methoxycarbonylethyl-1,6heptadiene-3,5-dione, named Shiga-Y5 (SY5) (Figure 1b), which was synthesized in our laboratory as a fluorine-19 magnetic resonance $\left({ }^{19} \mathrm{~F} \mathrm{MR}\right)$ probe to detect amyloid deposition in the Tg2576 mouse [23]. SY5 contains six fluorine atoms and bears a substitution at the C-4 position, influencing the ratio of keto to enol tautomer and its effects on amyloid $\beta$ (A $\beta$ ) aggregation [24]. Our previous study demonstrated that only SY5 is effective against A $\beta$ toxicity; it improved cognitive impairment, inhibited amyloid deposition and reduced glial activation in APP/PS1 mice [25].
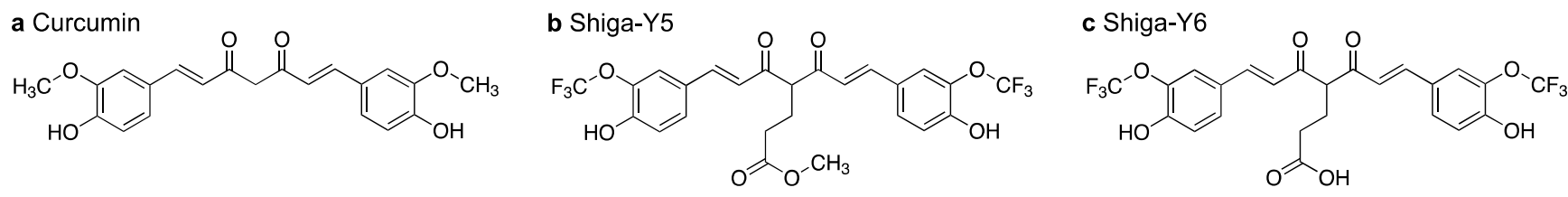

Figure 1. Chemical structure of curcumin, Shiga-Y5 and Shiga-Y6. (a) Curcumin, a yellow-orange pigment in turmeric. (b) Shiga-Y5 is a fluorinated curcumin derivative with methyl ester groups at the C-4 position. (c) Shiga-Y6 with carbonic acid groups at the C-4 position was obtained by the hydrolysis of Shiga-Y5.

Several studies have demonstrated the therapeutic effect of curcumin, as seen by the increased TXN protein expression [26] and decreased TXNIP protein expression [27] in cells subjected to oxidative stress. A curcumin derivative with the carbonic acid group named Shiga-Y6 (SY6) (Figure 1c) showed negative regulation on TXNIP expression in culture cells exposed to high glucose and endoplasmic reticulum stress inducer [28]. Our preliminary study showed that SY5 passes the blood-brain barrier (BBB), and the methyl ester group undergoes hydrolysis in the brain to produce SY6; however, the mechanism remains unclear. This finding suggests that acting as a prodrug of SY6 is a possible mechanism of action of SY5 to inhibit TXNIP, leading to the therapeutic effect in the AD model mice. Here, we investigated the role of SY5 as the prodrug of SY6 in the thioredoxin system, which might be a possible target for intervention in AD.

\section{Results}

\subsection{Gene Expression of TXN and TXNIP}

Our previous study using SY5 indicated that the dose of $200 \mathrm{mg} / \mathrm{kg}$ was tolerated and can cross the BBB after intravenous injection in APP/PS1 mice [23]. In this study, the same dose of SY5 $(200 \mathrm{mg} / \mathrm{kg}$ ) was administered by intraperitoneal injection (i.p). After $2 \mathrm{~h}$, the mice were sacrificed, the brain was quickly removed, and the cerebral cortex and liver were isolated and cut in half for the gene and protein expression analysis. In the brain's 
cerebral cortex, the TXN mRNA level was unchanged in APP/PS1 mice compared with WT mice. However, with SY5 treatment, the TXN mRNA level was significantly increased $(p=0.0285)$. In contrast, TXNIP mRNA level was significantly increased $(p=0.0224)$ in APP/PS1 mice compared with WT mice, and with SY5 treatment, TXNIP mRNA level was significantly decreased $(p=0.0072)$ compared to without treatment in APP/PS1 mice (Figure 2a). There were no significant differences in the liver in TXN or TXNIP mRNA levels between APP/PS1 and WT mice and between APP/PS1 mice with or without SY5 treatment (Figure 2b).

\section{a. Brain}

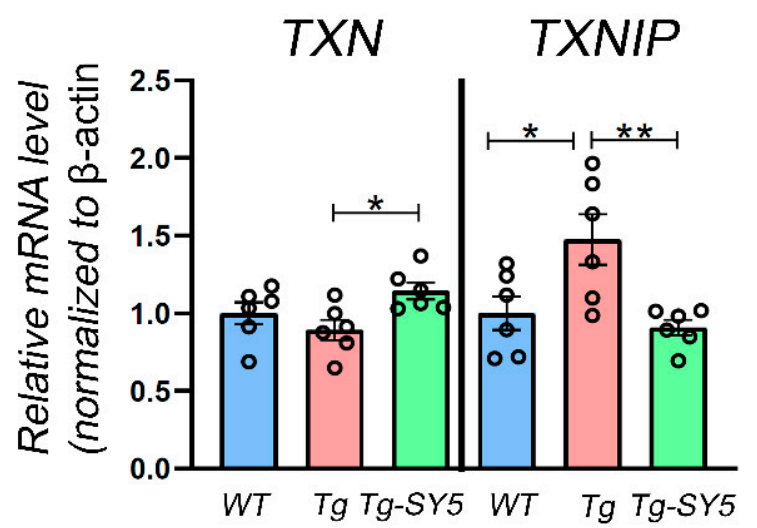

b. Liver

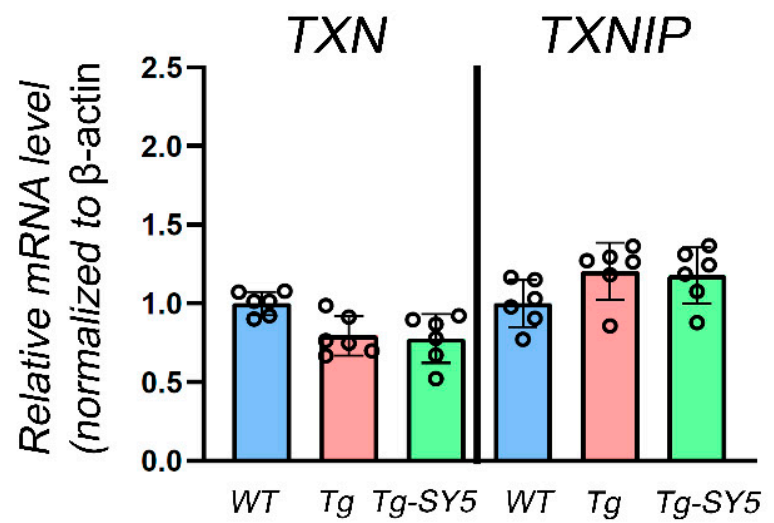

Figure 2. The TXN or TXNIP gene expression level in the amyloid precursor protein and presenilin 1 double transgenic $(\mathrm{APP} / \mathrm{PS} 1)$ mice in (a) brain and (b) liver. Data are presented as mean $\pm \operatorname{SEM}(n=6)$. Significance: ${ }^{* *} p<0.01,{ }^{*} p<0.05$.

\subsection{Protein Expression of TXN and TXNIP}

We further investigated the effect of SY5 on the protein level of TXN and TXNIP in APP/PS1 mice. Protein extracts from the cerebral cortex and the liver were electrophoresed on SDS gel, and the protein bands of TXN and TXNIP were detected at the estimated size of 12 and $52 \mathrm{kDa}$, respectively (Figure 3a,b). Full-length blots are presented in Supplementary Figures S1 and S2. In the brain's cerebral cortex, the TXN protein expression level showed a decreasing trend but was not statistically significant in APP/PS1 mice compared with WT mice. In contrast, there was a significant increase $(p=0.0039)$ in the TXN protein expression level with SY5 treatment than without treatment in APP/PS1 mice (Figure 3c). Furthermore, the TXNIP protein expression level demonstrated a significant increase $(p=0.0126)$ in APP/PS1 mice compared with WT mice; the increased level of TXNIP was significantly reversed $(p=0.0143)$ with SY5 treatment compared with without treatment in APP/PS1 mice (Figure 3d). Additionally, the ratio of TXN/TXNIP significantly decreased $(p=0.0131)$ in APP/PS1 compared with WT mice; however, the decreased ratio of TXN/TXNIP was more significantly reversed ( $p=0.0072)$ with SY5 treatment than without treatment in APP/PS1 mice (Figure 3e). Meanwhile, in the liver, consistent with the mRNA level, there were no significant differences in TXN or TXNIP protein expression level and the ratio of TXN/TXNIP between APP/PS1 and WT mice and between APP/PS1 mice with or without SY5 treatment (Figure 3f-h). 
a. Brain

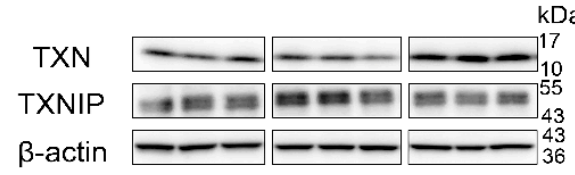

b. Liver

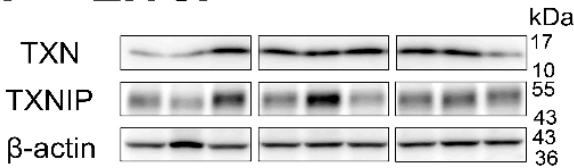

\section{Brain}

c.

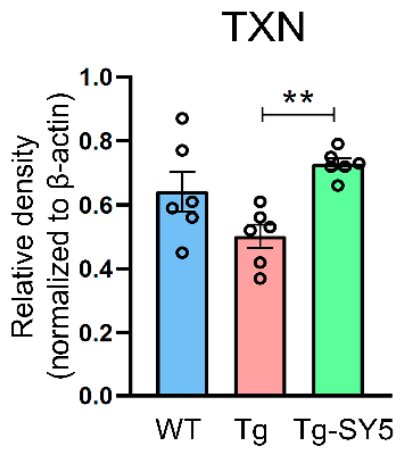

d.

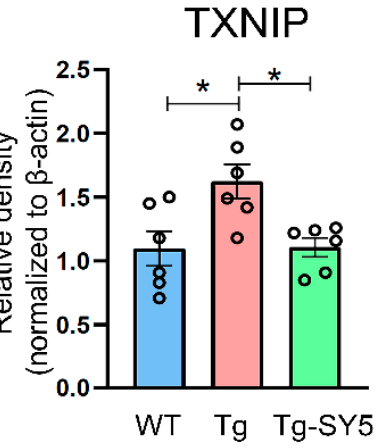

e.

TXN/TXNIP

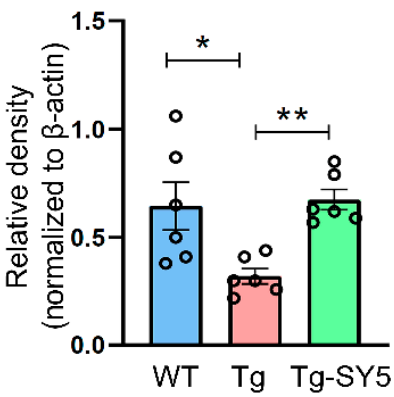

Liver

f.

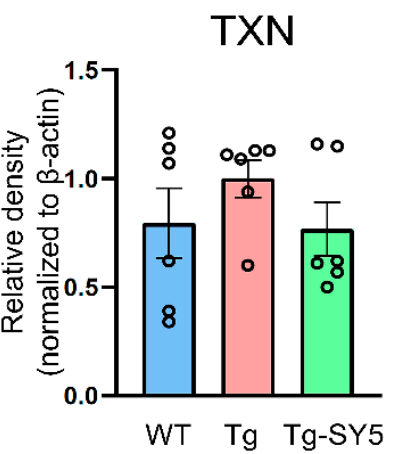

g.

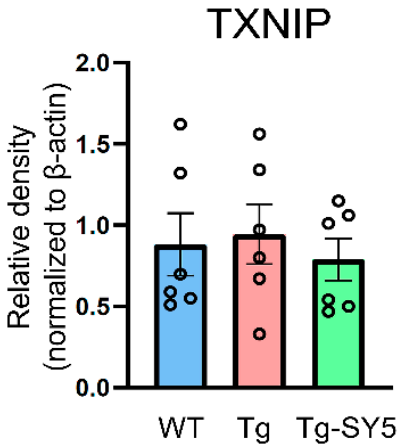

h.

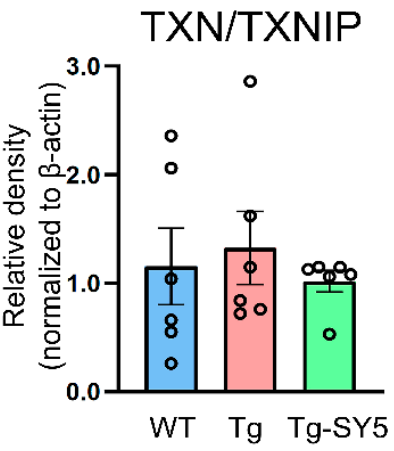

Figure 3. The TXN or TXNIP protein expression level in the APP/PS1 mice. Representative images of Western blotting for TXN, TXNIP, and $\beta$-actin in (a) the brain and (b) liver. Densitometric analysis of TXN or TXNIP and calculation of the ratio of TXN/TXNIP in the cerebral cortex of the brain (c-e) and the liver $(\mathbf{f}-\mathbf{h})$. Data are presented as mean $\pm \operatorname{SEM}(n=6)$. Significance: ${ }^{* *} p<0.01,{ }^{*} p<0.05$. Full-length blots are presented in Supplementary Figures S1 and S2.

\section{Discussion}

In this study, we investigated the role of SY5 in regulating TXN and TXNIP in APP/PS1 mice. It had been initially hypothesized that targeting TXNIP by lowering its levels would prevent the inhibitory binding to TXN, which might reduce oxidative stress. Our results show that the TXNIP protein expression level was initially upregulated in the brain of APP/PS1 mice; however, with SY5 treatment, it was downregulated and accompanied by the upregulation of TXN at the transcriptional and translational levels. In contrast, we found no changes in TXN or TXNIP levels in the liver, suggesting that SY5 acts as a signaling molecule targeting the thioredoxin system in the brain of APP/PS1 mice.

Consistent with the previous study, the protein expression of TXNIP increased significantly without changes in TXN in the brain of APP/PS1 mice at 9 and 12 months 
of age when $A \beta$ deposits had developed compared with wild-type mice [16]. Several studies have demonstrated that TXNIP is required to activate NLRP3 inflammasome, a prevalent proposed mechanism in mediating inflammation in $\operatorname{AD}[13,29,30]$. Activated NLRP3 recruited the adapter protein apoptosis-associated specklike (ASC) and pro-caspase 1 , leading to caspase 1 production and subsequent interleukin-1 $\beta$ (IL-1 $\beta$ ) maturation and release, activating signaling pathways and resulting in neuroinflammation and neuronal death $[13,31,32]$. Inhibiting TXNIP was elevated during disease development or in the presence of cellular stress factors, which showed several benefits, particularly in reversing the pathological outcomes. For example, the inhibitory effects of curcumin on TXNIP may have caused failed activation of the NLRP3 inflammasome, subsequently suppressing the upregulation of proinflammatory cytokines and improving paraquat-induced oxidative stress in lung fibroblast cells [27]. Similar effects of curcumin were also demonstrated whereby TXNIP/NLRP3 inflammasome activation was inhibited, suppressing endoplasmic reticulum stress and protecting neuronal cell survival in mice hippocampus-induced glutamate neurotoxicity [33].

Previously, we have synthesized and reported at least two ${ }^{19} \mathrm{~F}$ MR probes containing different novel contrast agents to detect amyloid deposits in the brain of transgenic mouse models of AD [34]. These include curcumin (Shiga-Y) [23] and styrylbenzoxazole derivatives (Shiga-X) [35], which possess fluorine substituents to detect ${ }^{19} \mathrm{~F}$ MR signals. MR sensitivity of ${ }^{19} \mathrm{~F}$ is high compared with various nuclei other than ${ }^{1} \mathrm{H}\left({ }^{1} \mathrm{H}, 100 \%\right.$; ${ }^{19} \mathrm{~F}$, $83 \% ;{ }^{31} \mathrm{P}, 6.6 \% ;{ }^{13} \mathrm{C}, 1.6 \%$ ). No detectable fluorine atoms exist in biological tissues (fluorine in bones and teeth is inappropriate for ${ }^{19} \mathrm{~F}$ MRI relaxation time), which could result in low endogenous background noise. Furthermore, the ${ }^{19} \mathrm{~F}$ atom is a nonradioactive isotope comprising $100 \%$ of naturally abundant fluorine. Thus, ${ }^{19} \mathrm{~F}$ MRI is a highly sensitive, readily available, low-background, and cost-effective approach once a suitable high-quality probe has been developed. Among more than $40{ }^{19} \mathrm{~F}$ MR probes containing curcumin derivatives synthesized in our laboratory, the one typically used for amyloid imaging in the mouse brain using MRI was SY5 [36]. SY5 contained six ${ }^{19} \mathrm{~F}$ atoms in two $\mathrm{CF}_{3}$ groups, which display a single sharp ${ }^{19} \mathrm{~F}$ nuclear magnetic resonance (NMR) signal in solution and could bind to senile plaques in human brain sections. However, when these chemicals were intravenously injected into the tail veins of the APP transgenic mouse model (Tg2576), only SY5 passed through the BBB and bound to A $\beta$ plaques (Supplementary Figure S3). In contrast, SY 6 did not bind to A $\beta$ plaques due to poor permeability into the brain (Supplementary Figure S3) [36].

Previous studies in our laboratory showed that SY6 demonstrated significantly greater activity in inhibiting TXNIP expression and enhancing TXN expression in cellular models of diabetes, endoplasmic reticulum stress, and inflammation while possessing the antiinflammatory properties of native curcumin [28]. However, SY6 could not cross the BBB, limiting its further investigation in an animal model. Our preliminary study showed that SY 5 could be converted to SY6 when entering the brain; however, the mechanism remains unclear. Thus, we speculate that the inhibitory effect of SY5 on TXNIP and TXN upregulation in the brain was possibly from the action exerted by SY6. However, the action exerted by SY5 on TXNIP may be independent of conversion to SY6. Further study is needed to discover more about the mechanism of action of SY5.

We also demonstrated that in the microenvironment surrounding A $\beta$ plaques, SY5, which bears a substitution at the $C-4$ position, likely exists in equilibrium between the free (keto) and bound (enol) forms to influence their effects on amyloid $\beta(A \beta)$ aggregation. Additionally, only the enol form of this compound can bind to $A \beta$ aggregates/fibrils [24] and $A \beta$ oligomers [37] but not to $A \beta$ monomers. Furthermore, ${ }^{19} \mathrm{~F}$ NMR signals displayed by SY 5 showed dose-dependently as it was hardly detected at a dose of $50 \mathrm{mg} / \mathrm{kg}$ but easily detected at a dose of $100 \mathrm{mg} / \mathrm{kg}$ and tolerable up to a dose of $200 \mathrm{mg} / \mathrm{kg}$ [23]. Histological analysis of SY5 following intravenous injection in APP/PS1 mice showed strong fluorescent signals in the cortex and hippocampus, with most of this signal colocalized with $A \beta$ immunoreactivity [23]. Furthermore, we demonstrated that only SY5 inhibited behavioral 
deficit, as seen in the water maze test, a significant reduction in latencies for the platform at days 5 and 6, compared with day 1 in APP/PS1 mice besides comparable time spent in the targeted quadrant to that in WT mice [25]. Our previous studies show that A $\beta$ in the form of fibrils and oligomers are targeted by SY5 and improved cognitive function in APP/PS1 mice. Possibly, there will be more targeted proteins to explain the mechanisms of action and therapeutic effects of this compound.

There were some limitations in this study, including no investigation regarding changes in TXNIP levels in SY5-injected wild-type mice, the effect of SY5 on cognitive function and $A \beta$ accumulation in the brain, and the detailed mechanism of how SY5 acts as a TXNIP modulator in the brain. Further study is needed to clarify these points.

Summarily, these data indicate directions for future studies for characterizing the properties of curcumin derivatives. We have produced many chemically modified curcumin derivatives that can be tested in these simple assays to modulate TXNIP and TXN expression.

\section{Materials and Methods}

\subsection{Animals}

All animal experiments were conducted according to the National Institutes of Health Guide for the Care and Use of Laboratory Animals and approved by the Institutional Ethics Committee of Shiga University of Medical Science (2021-6-10). APP/PS1 mice with a C57BL/ 6 background (Jackson Laboratory, Bar Harbor, ME, USA), expressing a chimeric mouse/human amyloid precursor protein with the K594N and M595L mutations linked to Swedish familial AD (Mo/HuAPP695swe) and human PS1, carrying the exon 9 deletion associated with familial AD [38] were used in this study. The mice were housed in standard laboratory cages at $23^{\circ} \mathrm{C}$ with free access to water and food in an SPF animal facility and maintained with a $12 \mathrm{~h}$ light/dark cycle with lights on from 8:00 a.m. to 8:00 p.m.

\subsection{Treatment Groups}

Shiga-Y5 was dissolved at a concentration of $10 \mathrm{mg} / \mathrm{mL}$ in saline containing $10 \%$ Cremophor EL. The WT mice $(n=6)$ aged $10-12$ months received an intraperitoneal injection (i.p.) of normal saline containing 10\% Cremophor EL. The APP/PS1 mice aged 10-12 months were divided into two groups, with six mice in each group and received i.p. normal saline (Tg) and Shiga-Y5 at $200 \mathrm{mg} / \mathrm{kg}$ (Tg-SY5). After $2 \mathrm{~h}$, the mice were sacrificed under deep anesthesia using sodium pentobarbital $(200 \mathrm{mg} / \mathrm{kg}$, i.p.); the brain was quickly removed from each mouse. The cerebral cortex tissues from the right hemisphere and the liver were isolated and snap-frozen in liquid nitrogen and stored at $-80^{\circ} \mathrm{C}$ until further use for gene and protein expression analysis.

\subsection{Preparation of Protein Extracts from Brain and Liver Tissue}

Brain and liver tissue were homogenized in 10 volumes of Tris-buffered saline (TBS; $25 \mathrm{mM}$ Tris- $\mathrm{HCl}$ (pH 7.5), $150 \mathrm{mM} \mathrm{NaCl}, 1 \mathrm{mM}$ EGTA, protease inhibitor cocktail (Roche Diagnostic, Mannheim, Germany) and phosphatase inhibitor cocktail (Roche Diagnostic)) added to Triton X-100 (1\% final concentration), kept on ice for $60 \mathrm{~min}$ and centrifuged at $10,000 \times g, 4^{\circ} \mathrm{C}$ for $15 \mathrm{~min}$. The supernatant was collected, and the protein concentration was determined using a Protein Assay Bicinchoninate kit (Nacalai Tesque, Kyoto, Japan).

\subsection{Western Blotting}

Proteins $(10 \mu \mathrm{g})$ in $4 \mathrm{x}$ sample buffer and 10x reducing buffer (Life Technologies, Waltham, MA, USA) were denatured at $95^{\circ} \mathrm{C}$ for $10 \mathrm{~min}$, applied to the lanes of precast $15 \%$ polyacrylamide gels (Wako Pure Chemicals, Osaka, Japan), electrophoresed, and transferred to polyvinylidene difluoride membranes (Immobilon-P; Merck Millipore, MA, USA). The membranes were blocked with $5 \%$ skim milk in Tris-buffered saline containing $1 \%$ Tween 20 (TBST) at room temperature for $1 \mathrm{~h}$, followed by overnight incubation at $4{ }^{\circ} \mathrm{C}$ with the primary antibodies including rabbit monoclonal antibodies against thioredoxin 
(ab273877; 1:1000; Abcam, Cambridge, UK), TXNIP (ab188865; 1:2000, Abcam) and mouse monoclonal antibody against $\beta$-actin (1:5000; Santa Cruz Biotechnology, Dallas, TX, USA). The membranes were further incubated with horseradish peroxidase-conjugated goat polyclonal antibody against rabbit immunoglobulin (Ig)G (1:10,000; Jackson ImmunoResearch, West Grove, PA, USA) and mouse IgG (1:10,000; Jackson ImmunoResearch) for $1 \mathrm{~h}$ at room temperature. Immunoreactivity proteins were visualized with a chemiluminescence substrate (SuperSignal West Pico PLUS Chemiluminescence Substrate; Thermo Fisher Scientific, Waltham, MA, USA) using Western blotting imager (Fusion Solo S, Vilber, Nantes, France). The band density was analyzed using image processing software (ImageJ; National Institutes of Health, Bathesda, MD, USA).

\subsection{RNA Isolation and Quantitative Polymerase Chain Reaction ( $q P C R$ )}

Total RNA was extracted from the cerebral cortex and the liver using RNeasy Lipid Tissue Mini and RNeasy Plus Universal Mini Kit (Qiagen, Hilden, Germany), respectively, following the manufacturer's protocol. RNA samples were reverse transcribed into cDNA using ReverTra Ace qPCR RT Master Mix with gDNA Remover kit (Toyobo, Osaka, Japan) in accordance with the manufacturer's protocol. qPCR was conducted in duplicate $10 \mu \mathrm{L}$ reactions containing 2- $\mu \mathrm{L}$ cDNA, 5- $\mu \mathrm{L}$ TaqMan Fast Advanced Master Mix (Applied Biosystem, Waltham, MA, USA), 0.5- $\mu$ L TaqMan Gene Expression assay (TXN, Mm00726847_s1; TXNIP, Mm00452393_m1; ACTB, Mm01205647_g1) (Applied Biosystem) and $3.5 \mu \mathrm{L}$ of RNase free water on a LightCycler 480 instrument (Roche Diagnostic) using the following cycling parameters: Uracil $\mathrm{N}$-glycosylase incubation at $50{ }^{\circ} \mathrm{C}$ for $2 \mathrm{~min}$, polymerase activation at $95^{\circ} \mathrm{C}$ for $2 \mathrm{~min}$, followed by 40 cycles of denaturation at $95^{\circ} \mathrm{C}$ for $1 \mathrm{~s}$, annealing/extension at $60^{\circ} \mathrm{C}$ for $20 \mathrm{~s}$.

\subsection{Statistical Analysis}

Statistical analyses were performed using GraphPad PRISM v.8 software (GraphPad Software, San Diego, CA, USA). Data are presented as the mean \pm standard error of the mean (SEM). Statistical comparisons between groups were performed using one-way ANOVA followed by Sidak post hoc test. The statistical significance of all tests was set at $p<0.05$.

\section{Patents}

Shiga University of Medical Science obtained a Japanese patent (JP2012-260046) on SY5 and SY6, with D.Y., H.T., and I.T. named as the inventors, and has submitted another Japanese patent application (JP2020-141272) on SY6, with D.Y., H.T., and I.T. named as the inventors.

Supplementary Materials: The following are available, Figure S1: Full-length blots in Figure 2a, Figure S2: Full-length blots in Figure 2b, Figure S3: ${ }^{19} \mathrm{~F}$ MRI using Shiga-Y5 and Shiga-Y6.

Author Contributions: Conceptualization, D.Y. and I.T.; formal analysis, A.P.A.; investigation, A.P.A. and D.Y.; resources, H.T. and I.T.; writing-original draft preparation, A.P.A.; writing-review and editing, Z.H.A.B., H.T., D.Y., I.T.; visualization, A.P.A.; supervision, D.Y. and I.T.; funding acquisition, H.T. and I.T. All authors have read and agreed to the published version of the manuscript.

Funding: This research was funded by JSPS KAKENHI, grant numbers JP19K12780 (H.T.).

Institutional Review Board Statement: The study was conducted according to the National Institutes of Health Guide for the Care and Use of Laboratory Animals and approved by the Institutional Ethics Committee of Shiga University of Medical Science (10 June 2021).

Informed Consent Statement: Not applicable.

Data Availability Statement: The data presented in this study are available on request from the corresponding author.

Acknowledgments: The authors would like to thank Yasuko Hata and the staff of the Central Research Laboratory, Shiga University of Medical Science, for their technical assistance. 
Conflicts of Interest: The authors declare no conflict of interest.

Sample Availability: Sample of the compounds are available from the authors.

\section{References}

1. Hu, J.; Yu, Y. The Function of Thioredoxin-Binding Protein-2 (TBP-2) in Different Diseases. Oxid. Med. Cell. Longev. 2018, 2018, 4582130. [CrossRef]

2. Alhawiti, N.M.; Al Mahri, S.; Aziz, M.A.; Malik, S.S.; Mohammad, S. TXNIP in Metabolic Regulation: Physiological Role and Therapeutic Outlook. Curr. Drug Targets 2017, 18, 1095-1103. [CrossRef] [PubMed]

3. Shalev, A. Minireview: Thioredoxin-interacting protein: Regulation and function in the pancreatic $\beta$-cell. Mol. Endocrinol. 2014, 28, 1211-1220. [CrossRef] [PubMed]

4. Thielen, L.; Shalev, A. Diabetes pathogenic mechanisms and potential new therapies based upon a novel target called TXNIP. Curr. Opin. Endocrinol. Diabetes Obes. 2018, 25, 75-80. [CrossRef] [PubMed]

5. Wondafrash, D.Z.; Nire'a, A.T.; Tafere, G.G.; Desta, D.M.; Berhe, D.A.; Zewdie, K.A. Thioredoxin-Interacting Protein as a Novel Potential Therapeutic Target in Diabetes Mellitus and Its Underlying Complications. Diabetes Metab. Syndr. Obes. 2020, $13,43-51$. [CrossRef]

6. Panse, M.; Kluth, O.; Lorza-Gil, E.; Kaiser, G.; Mühlbauer, E.; Schürmann, A.; Häring, H.-U.; Ullrich, S.; Gerst, F. Palmitate and insulin counteract glucose-induced thioredoxin interacting protein (TXNIP) expression in insulin secreting cells via distinct mechanisms. PLoS ONE 2018, 13, e0198016. [CrossRef]

7. Jia, J.-J.; Geng, W.-S.; Wang, Z.-Q.; Chen, L.; Zeng, X.-S. The role of thioredoxin system in cancer: Strategy for cancer therapy. Cancer Chemother. Pharmacol. 2019, 84, 453-470. [CrossRef]

8. Chen, Y.; Ning, J.; Cao, W.; Wang, S.; Du, T.; Jiang, J.; Feng, X.; Zhang, B. Research Progress of TXNIP as a Tumor Suppressor Gene Participating in the Metabolic Reprogramming and Oxidative Stress of Cancer Cells in Various Cancers. Front. Oncol. 2020, 10, 1861. [CrossRef]

9. Xie, M.; Xie, R.; Xie, S.; Wu, Y.; Wang, W.; Li, X.; Xu, Y.; Liu, B.; Zhou, Y.; Wang, T.; et al. Thioredoxin interacting protein (TXNIP) acts as a tumor suppressor in human prostate cancer. Cell Biol. Int. 2020, 44, 2094-2106. [CrossRef] [PubMed]

10. Morrison, J.A.; Pike, L.A.; Sams, S.B.; Sharma, V.; Zhou, Q.; Severson, J.J.; Tan, A.-C.; Wood, W.M.; Haugen, B.R. Thioredoxin interacting protein (TXNIP) is a novel tumor suppressor in thyroid cancer. Mol. Cancer 2014, 13, 62. [CrossRef]

11. DeTure, M.A.; Dickson, D.W. The neuropathological diagnosis of Alzheimer's disease. Mol. Neurodegener. 2019, 14, 32. [CrossRef]

12. Bloom, G.S. Amyloid- $\beta$ and tau: The trigger and bullet in Alzheimer disease pathogenesis. JAMA Neurol. 2014, 71, 505-508. [CrossRef] [PubMed]

13. Li, L.; Ismael, S.; Nasoohi, S.; Sakata, K.; Liao, F.-F.; McDonald, M.P.; Ishrat, T. Thioredoxin-Interacting Protein (TXNIP) Associated NLRP3 Inflammasome Activation in Human Alzheimer's Disease Brain. J. Alzheimer's Dis. 2019, 68, 255-265. [CrossRef]

14. Akterin, S.; Cowburn, R.F.; Miranda-Vizuete, A.; Jiménez, A.; Bogdanovic, N.; Winblad, B.; Cedazo-Minguez, A. Involvement of glutaredoxin-1 and thioredoxin-1 in $\beta$-amyloid toxicity and Alzheimer's disease. Cell Death Differ. 2006, 13, 1454-1465. [CrossRef] [PubMed]

15. Lovell, M.A.; Xie, C.; Gabbita, S.P.; Markesbery, W.R. Decreased thioredoxin and increased thioredoxin reductase levels in Alzheimer's disease brain. Free Radic. Biol. Med. 2000, 28, 418-427. [CrossRef]

16. Wang, Y.; Wang, Y.; Bharti, V.; Zhou, H.; Hoi, V.; Tan, H.; Wu, Z.; Nagakannan, P.; Eftekharpour, E.; Wang, J.-F. Upregulation of Thioredoxin-Interacting Protein in Brain of Amyloid- $\beta$ Protein Precursor/Presenilin 1 Transgenic Mice and Amyloid- $\beta$ Treated Neuronal Cells. J. Alzheimer's Dis. 2019, 72, 139-150. [CrossRef]

17. Mangialasche, F.; Polidori, M.C.; Monastero, R.; Ercolani, S.; Camarda, C.; Cecchetti, R.; Mecocci, P. Biomarkers of oxidative and nitrosative damage in Alzheimer's disease and mild cognitive impairment. Ageing Res. Rev. 2009, 8, 285-305. [CrossRef] [PubMed]

18. Mariani, E.; Polidori, M.C.; Cherubini, A.; Mecocci, P. Oxidative stress in brain aging, neurodegenerative and vascular diseases: An overview. J. Chromatogr. B. Anal. Technol. Biomed. Life Sci. 2005, 827, 65-75. [CrossRef]

19. Butterfield, D.A.; Poon, H.F.; St Clair, D.; Keller, J.N.; Pierce, W.M.; Klein, J.B.; Markesbery, W.R. Redox proteomics identification of oxidatively modified hippocampal proteins in mild cognitive impairment: Insights into the development of Alzheimer's disease. Neurobiol. Dis. 2006, 22, 223-232. [CrossRef]

20. Pan, Q.; Guo, K.; Xue, M.; Tu, Q. Estrogen protects neuroblastoma cell from amyloid- $\beta 42$ (A $\beta 42$ )-induced apoptosis via TXNIP/TRX axis and AMPK signaling. Neurochem. Int. 2020, 135, 104685. [CrossRef]

21. Wang, C.-Y.; Xu, Y.; Wang, X.; Guo, C.; Wang, T.; Wang, Z.-Y. Dl-3-n-Butylphthalide Inhibits NLRP3 Inflammasome and Mitigates Alzheimer's-Like Pathology via Nrf2-TXNIP-TrX Axis. Antioxid. Redox Signal. 2019, 30, 1411-1431. [CrossRef] [PubMed]

22. Priyadarsini, K.I. The chemistry of curcumin: From extraction to therapeutic agent. Molecules 2014, 19, 20091-20112. [CrossRef] [PubMed]

23. Yanagisawa, D.; Amatsubo, T.; Morikawa, S.; Taguchi, H.; Urushitani, M.; Shirai, N.; Hirao, K.; Shiino, A.; Inubushi, T.; Tooyama, I. In vivo detection of amyloid $\beta$ deposition using $19 \mathrm{~F}$ magnetic resonance imaging with a 19F-containing curcumin derivative in a mouse model of Alzheimer's disease. Neuroscience 2011, 184, 120-127. [CrossRef] [PubMed] 
24. Yanagisawa, D.; Shirai, N.; Amatsubo, T.; Taguchi, H.; Hirao, K.; Urushitani, M.; Morikawa, S.; Inubushi, T.; Kato, M.; Kato, F.; et al. Relationship between the tautomeric structures of curcumin derivatives and their Abeta-binding activities in the context of therapies for Alzheimer's disease. Biomaterials 2010, 31, 4179-4185. [CrossRef]

25. Yanagisawa, D.; Ibrahim, N.F.; Taguchi, H.; Morikawa, S.; Hirao, K.; Shirai, N.; Sogabe, T.; Tooyama, I. Curcumin derivative with the substitution at C-4 position, but not curcumin, is effective against amyloid pathology in APP/PS1 mice. Neurobiol. Aging 2015, 36, 201-210. [CrossRef] [PubMed]

26. Wu, J.-X.; Zhang, L.-Y.; Chen, Y.-L.; Yu, S.-S.; Zhao, Y.; Zhao, J. Curcumin pretreatment and post-treatment both improve the antioxidative ability of neurons with oxygen-glucose deprivation. Neural Regen. Res. 2015, 10, 481-489. [CrossRef]

27. Ren, Y.; Yang, Z.; Sun, Z.; Zhang, W.; Chen, X.; Nie, S. Curcumin relieves paraquat-induced lung injury through inhibiting the thioredoxin interacting protein/NLR pyrin domain containing 3-mediated inflammatory pathway. Mol. Med. Rep. 2019, 20, 5032-5040. [CrossRef]

28. Buyandelger, U.; Walker, D.G.; Taguchi, H.; Yanagisawa, D.; Tooyama, I. Novel fluorinated derivative of curcumin negatively regulates thioredoxin-interacting protein expression in retinal pigment epithelial and macrophage cells. Biochem. Biophys. Res. Commun. 2020, 532, 668-674. [CrossRef]

29. Ismael, S.; Wajidunnisa; Sakata, K.; McDonald, M.P.; Liao, F.-F.; Ishrat, T. ER stress associated TXNIP-NLRP3 inflammasome activation in hippocampus of human Alzheimer's disease. Neurochem. Int. 2021, 148, 105104. [CrossRef]

30. Qayyum, N.; Haseeb, M.; Kim, M.S.; Choi, S. Role of Thioredoxin-Interacting Protein in Diseases and Its Therapeutic Outlook. Int. J. Mol. Sci. 2021, 22, 2754. [CrossRef]

31. Heneka, M.T.; Kummer, M.P.; Stutz, A.; Delekate, A.; Schwartz, S.; Vieira-Saecker, A.; Griep, A.; Axt, D.; Remus, A.; Tzeng, T.-C.; et al. NLRP3 is activated in Alzheimer's disease and contributes to pathology in APP/PS1 mice. Nature 2013, 493, 674-678. [CrossRef] [PubMed]

32. Wright, A.L.; Zinn, R.; Hohensinn, B.; Konen, L.M.; Beynon, S.B.; Tan, R.P.; Clark, I.A.; Abdipranoto, A.; Vissel, B. Neuroinflammation and neuronal loss precede $\mathrm{A} \beta$ plaque deposition in the hAPP-J20 mouse model of Alzheimer's disease. PLoS ONE 2013, 8, e59586. [CrossRef] [PubMed]

33. Li, Y.; Li, J.; Li, S.; Li, Y.; Wang, X.; Liu, B.; Fu, Q.; Ma, S. Curcumin attenuates glutamate neurotoxicity in the hippocampus by suppression of ER stress-associated TXNIP/NLRP3 inflammasome activation in a manner dependent on AMPK. Toxicol. Appl. Pharmacol. 2015, 286, 53-63. [CrossRef]

34. Tooyama, I.; Yanagisawa, D.; Taguchi, H.; Kato, T.; Hirao, K.; Shirai, N.; Sogabe, T.; Ibrahim, N.F.; Inubushi, T.; Morikawa, S. Amyloid imaging using fluorine-19 magnetic resonance imaging ((19)F-MRI). Ageing Res. Rev. 2016, 30, 85-94. [CrossRef] [PubMed]

35. Yanagisawa, D.; Taguchi, H.; Ibrahim, N.F.; Morikawa, S.; Shiino, A.; Inubushi, T.; Hirao, K.; Shirai, N.; Sogabe, T.; Tooyama, I. Preferred features of a fluorine-19 MRI probe for amyloid detection in the brain. J. Alzheimer's Dis. 2014, 39, 617-631. [CrossRef] [PubMed]

36. Taguchi, H.; Yanagisawa, D.; Morikawa, S.; Hirao, K.; Shirai, N.; Tooyama, I. Synthesis and Tautomerism of Curcumin Derivatives and Related Compounds. Aust. J. Chem. 2015, 68, 224-229. [CrossRef]

37. Yanagisawa, D.; Taguchi, H.; Yamamoto, A.; Shirai, N.; Hirao, K.; Tooyama, I. Curcuminoid binds to amyloid- $\beta 1-42$ oligomer and fibril. J. Alzheimer's Dis. 2011, 24 (Suppl. 2), 33-42. [CrossRef]

38. Jankowsky, J.L.; Fadale, D.J.; Anderson, J.; Xu, G.M.; Gonzales, V.; Jenkins, N.A.; Copeland, N.G.; Lee, M.K.; Younkin, L.H.; Wagner, S.L.; et al. Mutant presenilins specifically elevate the levels of the 42 residue beta-amyloid peptide in vivo: Evidence for augmentation of a 42-specific gamma secretase. Hum. Mol. Genet. 2004, 13, 159-170. [CrossRef] 